\title{
Processos de governação da ciência: O debate em torno do modelo de financiamento das unidades de investigação em Portugal
}

Processes of science governance: The debate around the model for funding research units in Portugal

Processus de la gestion de l'activité scientifique : Le débat autour du modèle du fonctionnement des unités de recherche au Portugal

Tiago Santos Pereira

\section{OpenEdition}

\section{Journals}

Edição electrónica

URL: http://journals.openedition.org/rccs/1044

DOI: $10.4000 /$ rccs. 1044

ISSN: 2182-7435

\section{Editora}

Centro de Estudos Sociais da Universidade de Coimbra

Edição impressa

Data de publição: 1 Dezembro 2004

Paginação: 05-32

ISSN: 0254-1106

Refêrencia eletrónica

Tiago Santos Pereira, "Processos de governação da ciência: O debate em torno do modelo de financiamento das unidades de investigação em Portugal », Revista Crítica de Ciências Sociais [Online] 70 | 2004, colocado online no dia 01 outubro 2012, criado a 01 maio 2019. URL : http:// journals.openedition.org/rccs/1044; DOI : 10.4000/rccs.1044 


\section{Processos de governação da ciência: O debate em torno do modelo de financiamento das unidades de investigação em Portugal}

Com a crescente insistência das políticas públicas nos impactos económicos e sociais da investigação, os modelos de governação da ciência têm sofrido alterações. O modelo tradicional, com base na autonomia da ciência, tem vindo a ser substituído por novos modelos que colocam maior ênfase nos processos de prestação de contas, no quadro de uma maior co-responsabilização entre Estado e investigadores. Até que ponto este processo consegue ser equilibrado perante os diversos impactos da investigação e as diferentes áreas científicas é uma questão aqui discutida. O presente artigo analisa estes desenvolvimentos através de um estudo de caso do recente debate público em torno de um novo modelo de financiamento das unidades de investigação em Portugal.

\section{Introdução}

As novas exigências para uma maior prestação de contas das actividades de investigação têm levado, em diferentes países, à implementação de modelos de financiamento institucional directamente dependentes de mecanismos de avaliação. Estes novos mecanismos de controlo sobre a ciência, da parte de variados actores sociais, não são apenas um desafio para os investigadores. São-no também para os decisores públicos, que frequentemente se vêem na posição de gerir a necessidade declarada, quer pela indústria, quer pelo público em geral, de uma maior responsabilização da actividade científica, respondendo a solicitações que vão por vezes em direcções opostas e são difíceis de equilibrar ou de integrar.

Neste processo, os novos modelos de prestação de contas tendem a favorecer a valorização de resultados directos da investigação, os quais podem mais facilmente ser contabilizados, tais como publicações ou patentes. Outro tipo de impactos, de natureza indirecta, são mais dificilmente contabilizáveis. Deste modo os processos de avaliação de natureza quantitativa ganham relevância, funcionando como um mecanismo de selecção das actividades dos investigadores. 
Estas tensões tornaram-se particularmente evidentes num debate público recente em Portugal sobre uma nova proposta de financiamento das unidades de investigação. Esta proposta de reestruturação do processo de financiamento existente colocou precisamente uma grande ênfase nos procedimentos quantitativos em contraponto com a anterior dependência quase directa de um processo de avaliação qualitativa das unidades de investigação. A proposta foi colocada em discussão pública pelo próprio Ministério da Ciência e do Ensino Superior num fórum aberto na sua página de internet, tendo despoletado um intenso debate que não se restringiu a esse espaço de acesso privilegiado aos intervenientes mais directos, mas teve amplo eco em diversos jornais nacionais. A elevada participação de membros da comunidade científica, relativamente "silenciosa" em anos recentes, foi particularmente evidente.

Tendo por base o debate público gerado por esta proposta, este artigo irá analisar, na secção que se segue, os novos processos de governação da ciência, em que a anterior delegação do Estado na comunidade científica é substituída por novos mecanismos de controlo e de responsabilização da ciência. A terceira secção, analisando o debate em torno do novo modelo de financiamento das unidades de investigação em Portugal, discute o modo como os novos processos de avaliação, tendendo a privilegiar a avaliação quantitativa, reflectem uma perspectiva desequilibrada da actividade científica. A secção final conclui argumentando que, ainda que parcialmente em linha com desenvolvimentos internacionais nos processos de governação da ciência, este modelo, ao colocar ênfase em resultados directos em detrimento de outras contribuições indirectas da ciência, reflecte desenvolvimentos recentes que não são transversais a todas as áreas científicas, não incorporando, assim, uma visão multidimensional da actividade científica.

\section{Uma redefinição da relação entre ciência e Estado}

A maior importância atribuída ao conhecimento como factor de produção nos modelos económicos actuais, patente em expressões como "economia baseada no conhecimento", sugere uma associação directa entre as actividades de criação de novos conhecimentos, como o são tipicamente as actividades de investigação, e a competitividade internacional. No entanto, é também esta mesma importância destas actividades, e o sucesso da universidade nas suas funções, que criou nova procura, pressões e exigências em torno da investigação.

Neste contexto, a investigação académica, que correspondia a um modelo de auto-organização da comunidade científica, tem vindo a ser alvo de uma redefinição do seu modelo de governação e da sua relação com o 
Estado, principal fonte de financiamento. Também as universidades, tradicionalmente no centro destas actividades, têm vindo a perder a sua posição monopolista com a participação de novas instituições na produção de conhecimento, como defendido por diversos autores (Gibbons et al., 1994; Santos, 1994).

Michael Gibbons e os seus co-autores defenderam que este processo constitui mesmo um novo modo de produção de conhecimentos, que apelidaram Modo 2 em oposição a um anterior Modo 1 de produção de conhecimentos. Para além desta heterogeneidade e diversidade organizacional da produção de conhecimentos, esta mudança é caracterizada pela produção de conhecimentos no contexto da aplicação, em transdisciplinaridade e não apenas regulada pela lógica disciplinar, com novas formas de responsabilização social e de reflexividade bem como de controlo de qualidade, multidimensional e envolvendo novos actores.

Sousa Santos (1994) identifica processos semelhantes de mudança na universidade, considerando que ela está perante uma tripla crise, de begemonia, de legitimidade e institucional. Enquadra-se particularmente nesta noção de crise institucional a procura de novos critérios de eficácia e produtividade, levando, assim, a uma redefinição do impacto das diferentes funções da universidade, elas próprias em transformação, e a uma utilização de novos modelos de avaliação. Estes processos de avaliação tendem no entanto a favorecer as actividades de curto prazo, e nem sempre englobam todo o espectro de actividades ou de benefícios associados com a investigação académica (cf. Salter e Martin, 2001). Impõem-se assim, implicitamente, novos modelos de incentivos entre as diversas actividades.

Se, no curto prazo, o impacto da universidade se traduz frequentemente em impactos económicos, mais facilmente demonstráveis (patentes, empresas spin-off, etc.), a sua legitimidade vai necessariamente para além destes limites temporais ou mesmo sectoriais. A universidade deve também assegurar a sua legitimidade futura e a sustentabilidade das nossas sociedades, garantindo o desenvolvimento de investigação em temas de importância futura ou mesmo no presente, mas com fracos dividendos económicos, como o são, por exemplo, a malária e a tuberculose, nos quais as empresas não estão dispostas a investir. Deve, assim, garantir a existência de uma base de conhecimento científico comum, também necessária às empresas no futuro e não apenas no presente (Pavitt, 1991). Mas a sua legitimidade não pode derivar apenas da sua contribuição directa para as actividades empresariais. Essa contribuição deve assegurar também a participação em processos públicos de decisão, contextualisando o conhecimento e articulando também a visão da 'sociedade de risco' (Nowotny et al., 2001). 
É precisamente a multiplicidade de objectivos da investigação que está em risco com os novos modelos de avaliação. Ainda que com uma dinâmica renovada, esta tensão não é apenas característica da função de investigação da universidade, estando igualmente presente na relação entre as diferentes funções da universidade (ensino, investigação e extensão), mas já se vem também aprofundando há largos anos. Já em 1963 Clark Kerr (1995), então presidente da Universidade da Califórnia, ilustrou esta tendência ao caracterizar a "multiversidade", com os seus diferentes objectivos e públicos, reconhecendo ao mesmo tempo as tensões emergentes de tal multiplicidade de funções.

\subsection{De um modelo de autonomia para uma co-responsabilização?}

Em resultado da importante contribuição da investigação para o desfecho da Segunda Guerra Mundial, Vannevar Bush (1945) propôs ao Presidente Roosevelt as bases para a política científica norte-americana, que vieram a constituir o modelo de formulação de política científica central do pós-guerra. $\mathrm{O}$ "contrato social para a ciência" ${ }^{1}$ subjacente, que regulava a relação entre os investigadores e o Estado, tornava clara a importância das actividades científicas para o benefício dos objectivos sociais, económicos e políticos da sociedade americana, e demarcava também claramente a fronteira entre cientistas e sociedade. Este contrato social traduziu-se numa divisão de funções entre o Estado e os cientistas, competindo ao Estado a provisão de financiamento e condições necessárias à obtenção, pelos cientistas, de novos conhecimentos e invenções correspondentes aos objectivos esperados para a melhoria do bem-estar social. Nas condições de tal contrato, os cientistas retinham a autonomia sobre as suas actividades e modelo de organização, através das suas próprias normas de conduta e mecanismos internos de responsabilização e validação do conhecimento, no que Polanyi (1962) apelidou de República da ciência. Em contrapartida, esperava-se que eles fornecessem a base de conhecimento para lidar com os futuros desafios da sociedade. Nas palavras de Vannevar Bush, "sem progresso científico, nenhum nível de realização em outras direcções pode assegurar a nossa saúde, prosperidade e segurança enquanto nação do mundo moderno" (Bush, 1945). A "retórica do contrato social para a ciência”, como descrita por Guston (2000), "invoca as responsabilidades voluntárias mas mútuas entre o governo e a ciência, a produção do bem público de investigação e o investimento na prosperidade futura que é a investigação".

\footnotetext{
${ }^{1}$ Expressão que, no entanto, como salientado por Guston (2000), não era explicitamente utilizada por Vannevar Bush.
} 
No entanto, este contrato social tem vindo a ser crescentemente questionado. Por um lado, a "prosperidade futura que é a investigação" é esperada cada vez mais no presente e não apenas como uma promessa futura. Por outro lado, a autonomia e responsabilização interna do sistema de investigação têm sido postas em questão. A tensão entre política e ciência originou uma redefinição do "contrato social para a ciência", conforme Guston (2000) salienta. Do modelo inicial, baseado na confiança e autonomia da ciência, a nova formulação assenta em novas formas de garantia conjunta para estabilizar a fronteira entre política e ciência através do que designou por organizações de fronteira. Estas organizações de fronteira "envolvem a participação de actores dos dois lados da fronteira, bem como de profissionais que actuam numa função de mediação [e] existem na fronteira entre os dois mundos sociais relativamente distintos da política e da ciência, mas que têm meios diferentes de prestação de contas entre si” (Guston, 2000).

Se, no modelo anterior, a autonomia privilegiava as regras académicas relativamente às ligações com outros actores, surgem também dúvidas sobre se um novo modelo será capaz de equilibrar os diferentes objectivos das actividades de investigação. Como defendido por Slaughter e Rhoades (1996) com base na sua análise de políticas para a investigação académica nos EUA, estas têm vindo a tornar-se reféns do que apelidaram uma "coligação para políticas de competitividade", revelando, assim, a dificuldade do surgimento de outros actores no espaço da formulação de políticas científicas. Um exemplo claro tem sido a política de apoio à comercialização e patenteamento académico, com a referência que se torna canónica à Lei Bayh-Dole, de 1980, nos EUA. Ainda que as provas do impacto económico desta legislação seja limitadas, ou mesmo fortemente questionadas por alguns autores (e.g. Mowery et al., 2001), ela tem sido amplamente invocada no âmbito internacional, nomeadamente na Europa, sendo um dos principais pontos em comum das políticas de investigação de diversos países, no que é um exemplo claro da importância atribuída à comercialização e a indicadores de resultados do impacto no curto prazo da investigação como o são as patentes académicas. O título de uma recente publicação da OCDE - Turning Science into Business (2003a) - é igualmente indicativo da importância do modelo político para a investigação académica baseado na competitividade, ainda que outro relatório da mesma organização indique entre os principais desafios na governação da investigação pública (OCDE, 2003b) responder a um leque diversificado de actores, evidenciando a tensão existente.

Mas mesmo que os discursos políticos mantenham uma visão alargada dos objectivos da investigação, dando relevância adequada aos seus contributos para o bem-estar social e aos benefícios a longo prazo da investigação, 
é essencial a implementação de incentivos apropriados (Dasgupta e David, 1994), capazes de reflectir as intenções políticas.

De acordo com Soo e Carson (2004), Clark Kerr considerava que uma das funções do reitor e da administração universitária era, precisamente, a de mediação entre as tensões emergentes da "multiversidade". Já Nowotny et al. sugerem que as agências financiadoras ${ }^{2}$ exercem agora esta posição de fronteira:

Tradicionalmente, o sistema europeu de conselhos de investigação tem sido liderado por cientistas para benefício da ciência. Mas as últimas duas décadas têm registado mudanças drásticas nas funções, metas e objectivos de muitos dos sistemas nacionais de conselhos de investigação. A forte crença na auto-governação (ainda que com bastante sucesso no passado) tem sido alvo de fortes críticas. (Nowotny et al., 2001: 75)

O caso que, a seguir, se analisa em maior detalhe corresponde precisamente a uma proposta de um novo modelo de avaliação e de financiamento de unidades de investigação, que pretende introduzir uma nova estrutura de incentivos para a investigação em Portugal. Mas ainda que a implementação deste programa esteja a cargo da Fundação para a Ciência e a Tecnologia, este novo modelo é proposto directamente pelo Ministério, não correspondendo assim ao novo modelo proposto por Guston (2000) de intervenção de instituições de fronteira.

\section{Um novo modelo de financiamento das unidades de investigação}

A relação entre ciência e Estado, em Portugal, tem vindo a evoluir em anos recentes, nomeadamente tendo em conta o papel central do sector universitário no sistema de investigação. ${ }^{3}$ Com fraca tradição de responsabilização da academia, a institucionalização de um processo de avaliação das unidades de investigação com carácter plurianual e recurso a avaliadores internacionais teve um papel central neste domínio. Este processo foi mesmo considerado como um dos principais resultados da implementação de um Ministério da Ciência e da Tecnologia, na segunda metade dos anos 90. ${ }^{4}$ Ainda que este processo tenha sido iniciado anteriormente (FCT, 2004), a sua institucionalização durante este período e a iniciativa de recorrer a painéis

\footnotetext{
${ }^{2}$ Research councils no original, sendo que o conceito original inclui desde logo, para além da função de financiamento aqui traduzida, também uma noção de independência do governo e de intermediação entre o Estado e a comunidade científica. O sistema português tende a desenvolver-se nesta direcção, mas ainda a título exploratório. A nomeação de conselhos científicos na Fundação para a Ciência e Tecnologia é um pequeno exemplo.

${ }_{3}^{3}$ Incluindo também instituições privadas sem fins lucrativos associadas com universidades.

${ }^{4}$ Cf. "Cientistas mobilizam-se", Diário de Notícias, 28 de Fevereiro de 2002.
} 
de avaliadores maioritariamente internacionais concedeu-lhe maior credibilidade e visibilidade perante o público em geral, tornando-o em prática da governação da ciência. Ao dar maior visibilidade a esta prática, nomeadamente através da cobertura da imprensa e da disponibilização de informação na internet, introduziu-se também um novo discurso de prestação de contas do sistema de investigação.

\subsection{O modelo de financiamento anterior}

Desde 1994 que a Fundação para a Ciência e a Tecnologia (então JNICT) tem em curso um programa de avaliação e financiamento das unidades de investigação, de carácter plurianual.

Este "Programa de Financiamento Plurianual de Unidades de I\&D" (como é identificado) baseava-se em dois conceitos de base. Em primeiro lugar, o programa concedia autonomia às unidades de investigação através da atribuição de financiamento não direccionado. Este financiamento era essencialmente considerado como uma contribuição para a institucionalização das unidades de investigação, sendo utilizado em despesas gerais ou financiamentos específicos da unidade, desde investigação a actividades de divulgação. Com base no modelo de autonomia da ciência, este programa pretendia contribuir, assim, para aumentar a capacidade das unidades de investigação de definirem e implementarem os seus objectivos científicos. O programa impunha apenas requisitos limitados para a definição das unidades, nomeadamente no relativo à dimensão, mas enfatizava aspectos da sua organização científica, estrutura científica, de coordenação e aconselhamento. Em segundo lugar, a implementação da avaliação institucional plurianual, e a sua publicitação, foi considerada como uma medida de "certificação" dos resultados das unidades e do sistema de investigação como um todo e como prémio pelos resultados individuais de cada unidade. A utilização de painéis de avaliação internacionais pretendia ultrapassar os riscos da criação de "old boys networks", típicos de pequenos sistemas de investigação, onde a fronteira entre avaliadores e avaliados é frequentemente difusa.

A institucionalização do processo regular de avaliação, ainda que não isenta de crítica (Pereira, 2004), teve um papel importante no desenvolvimento recente do sistema de investigação. O processo de avaliação subjacente era essencialmente qualitativo, com base na avaliação por pares. ${ }^{5}$ Os

\footnotetext{
${ }^{5}$ No entanto, uma outra medida implementada durante a gestão do ministro Mariano Gago foi a publicação, pelo Observatório das Ciências e das Tecnologias, de relatórios anuais das publicações portuguesas nas bases de dados do ISI. Esta medida foi precisamente apresentada como tendo o objectivo de aumentar a transparência do sistema, pela sua (suposta) objectividade, através da identificação de trabalhos de qualidade internacional realizado pelos investigadores nacionais ( $c f$. "Os livros da verdade", Público, 7 de Maio de 1998).
} 
painéis baseavam a sua avaliação em documentação preparada por cada unidade, incluindo um relatório de actividades do período considerado, a que se juntava uma curta visita dos membros do painel à unidade. Deste modo, sem orientações muito restritas, o processo de avaliação podia acolher variações entre áreas científicas, valorizando assim os diferentes tipos de actividades desenvolvidas pelas unidades de investigação e contextualizando os resultados de cada unidade nos padrões de actividade da respectiva área. Os resultados (passíveis de eventual recurso) eram posteriormente publicitados, em conjunto com os relatórios dos painéis de avaliação.

O exercício de avaliação tinha um impacto directo na atribuição de financiamento às unidades, o qual era variável com o resultado da avaliação da unidade e o respectivo número de doutorados. Numa escala de cinco valores, entre "Fraco" e "Excelente", as unidades classificadas com "Fraco" (um número reduzido em cada processo de avaliação) não recebiam financiamento, enquanto, no topo superior, as unidades classificadas com "Muito Bom" e "Excelente" recebiam financiamentos idênticos por doutorado. Tendo incentivos à qualidade, não havia no entanto incentivos específicos à "excelência". Para além deste "financiamento de base", os avaliadores podiam recomendar financiamento suplementar, o "financiamento programático", vocacionado para solucionar problemas que os painéis considerassem como fortemente limitativos do desenvolvimento da unidade de investigação, como, por exemplo, para o apoio à aquisição de equipamento específico.

Este mecanismo de financiamento institucional corresponde, de um modo genérico, a um modelo de financiamento com base no desempenho, tal como o de modelos existentes noutros países (Geuna e Martin, 2003), nomeadamente no que correspondia ao financiamento de base.

As críticas suscitadas por este modelo eram reduzidas, e maioritariamente efectuadas por ocasião da publicitação dos resultados, assentando em dois aspectos principais. A ênfase em painéis internacionais para assegurar a independência dos painéis, justificada em particular pela pequena dimensão da comunidade científica nacional, não era necessariamente suficiente para garantir tal independência. Na verdade, quer devido às redes internacionais dos investigadores portugueses, quer devido à diferente representação de certas áreas do conhecimento ou tendências disciplinares, os painéis poderiam ter maior proximidade de determinadas redes em detrimento de outras. Os painéis internacionais poderiam também privilegiar a agenda de investigação internacional em detrimento de temas de investigação de interesse específico no contexto nacional. 
A diferenciação entre o financiamento programático e o financiamento de base, e a sua justificação, foi também objecto de crítica. Enquanto o financiamento de base era directamente dependente da avaliação da qualidade da unidade, o financiamento programático dependia apenas de recomendações específicas do painel nesse sentido, correspondendo, por vezes, a níveis de financiamento significativos. Deste modo, uma unidade de investigação com uma classificação inferior poderia receber um financiamento por doutorado superior a uma unidade classificada com maior qualidade. Ainda que o discurso político enfatizasse a "transparência" e "abertura", estas eram necessariamente relativas (Pereira, 2004).

\subsection{O contexto político}

Ainda que o apoio às políticas existentes fosse muito homogéneo na comunidade científica, levando mesmo a variadas declarações públicas de apoio à política ministerial em vésperas das eleições legislativas de $2002,{ }^{6}$ inclusive por parte de comentadores da oposição, ${ }^{7}$ este apoio não suscitava eco muito significativo para além dos intervenientes directos, não consubstanciando assim a existência de um verdadeiro 'contrato social para a ciência' em Portugal. Como referido por um investigador durante o recente debate público do modelo de financiamento:

Infelizmente, até à data, não foi criada uma cultura científica que fortaleça a nossa democracia e muito menos a inversa. Como tal, os responsáveis políticos por esta pasta não têm sido sujeitos ao escrutínio de que são alvos os colegas da saúde ou das finanças. Em abono da verdade, tão pouco as oposições parlamentares (independentemente da cor política) ajudam a controlar a acção governativa ou sugerem alternativas meritórias. Em suma, a política de ciência em Portugal revela um insustentável défice democrático. (Ricardo Pimenta-Araújo, "Um protesto pela ciência!”, Público, 12 de Maio de 2004)

$\mathrm{Na}$ verdade, a participação ou acompanhamento dos processos de formulação de políticas públicas para a investigação reflecte o reduzido leque de actores que realizam investigação em Portugal, onde a participação do sector privado em actividades de investigação é das mais baixas dos países da OCDE. Assim, ainda que as políticas de investigação registem um apoio substancial, os seus benefícios directos, evidentes quanto a outros sectores da sociedade, são menos significativos.

${ }^{6}$ Cf. "Cientistas mobilizam-se", Diário de Notícias, 28 de Fevereiro de 2002.

7 Cf. “'Asneiras' e cansaço conduziram à derrota”, Diário de Notícias, 15 de Março de 2002. 
É neste contexto que o novo governo que toma posse em Abril de 2002 apresenta uma inflexão nas políticas para o sector, salientando a importância de uma maior participação do sector privado na investigação. Este discurso não é apenas reflexo de uma orientação geral de cariz mais neo-liberal das políticas do novo governo mas também de um diferente entendimento do modelo de prestação de contas do sector público de investigação, que coloca ênfase nos impactos directos da investigação. Esta abordagem encontrou também paralelo em iniciativas comunitárias que contestaram a utilização dos fundos estruturais na área da ciência, tecnologia e inovação pelo anterior executivo, auditando o respectivo Programa Operacional da Ciência, Tecnologia e Inovação (POCTI).

Estes processos focavam em grande parte procedimentos de cariz burocrático, que o entendimento de autonomia da comunidade científica leva muitas vezes a menosprezar, mas levantavam também dúvidas quanto à natureza estrutural de algumas medidas, que os financiamentos no âmbito do Quadro Comunitário de Apoio (QCA) pressupõem. Algumas das questões subjacentes a este processo vão ao cerne das políticas de investigação e da sua justificação: o que deve ser considerado um investimento estrutural quando se trata de conhecimento? Quais são os resultados e impactos esperados destas medidas? Como escolher e avaliar opções de políticas ou projectos propostos? Estas questões são centrais a um (eventual) "contrato social para a ciência”. Seguindo Guston (2000), é a aceitação ou reformulação desse contrato que se negoceia, como pano de fundo.

Uma das medidas questionadas neste processo foi precisamente o 'Programa de Financiamento Plurianual de Unidades de Investigação', tendo sido levantadas dúvidas ao seu modelo de prestação de contas, visto que o financiamento não pressupunha uma definição clara das actividades correspondentes ou dos resultados esperados (CE, 2003). Do ponto de vista político, essa questão resultava directamente do modelo de governação implementado, o qual correspondia a uma opção política. No entanto, do ponto de vista administrativo, nomeadamente no contexto dos fundos estruturais comunitários, considerava-se que a justificação do financiamento ${ }^{8}$ não poderia ser encontrada no passado, mas estar consubstanciada nas actividades propostas e no seu impacto estrutural. Ainda que o processo de avaliação incluísse a apresentação de um plano de actividades, este não era vinculativo e tinha um peso muito reduzido na avaliação das unidades comparativamente aos resultados obtidos no período anterior, pelo que não justificava

\footnotetext{
${ }^{8}$ É necessário diferenciar aqui a justificação da aprovação da concessão do financiamento, como um todo, da justificação das despesas, sendo que era o primeiro aspecto que estava em discussão.
} 
ex ante o impacto esperado. De facto, a institucionalização da avaliação, precisamente um dos seus pontos fortes, estava em parte em contradição com o seu impacto estrutural. ${ }^{9}$

Esta questão da apropriação de resultados, ou de impactos, está directamente relacionada com o modelo de prestação de contas subjacente e, por este meio, com o modelo de governação da ciência. Exemplifica também como o discurso político sobre a economia baseada no conhecimento, ainda que tendo já ultrapassado o círculo das políticas de ciência e inovação, tem ainda fortes barreiras à sua apropriação por outras políticas sectoriais, onde os modelos tradicionais de prestação de contas estão mais directamente relacionados com produtos físicos ou impactos mensuráveis e não com a imaterialidade do conhecimento. Estas barreiras, evidentes nestes processos de negociação, tornam também claro o "trabalho de fronteira" (Gieryn, 1995) de diferentes actores nas formas de entendimento da relação entre ciência e sociedade e de separação entre estas. Como utilizar a racionalidade económica (e que modelos de racionalidade) na análise das práticas de investigação ou como considerar o impacto estrutural da investigação na economia são assim questões subjacentes.

Com um período de tempo limitado para contabilizar os impactos da implementação das políticas estruturais, aumentam os incentivos para dar maior ênfase aos resultados materiais (em oposição aos imateriais), no curto prazo, destas políticas e, em particular, no domínio económico.

É neste contexto, de cariz político, que a apresentação de um novo modelo de financiamento das unidades de investigação, sem qualquer discussão prévia da validade do modelo existente, que não a resultante do processo de auditoria comunitária, e sem a formulação de uma argumentação explícita da mudança proposta, que não a do genérico discurso político sobre o (re)centramento do sistema no sentido de promover "o conhecimento científico, pelas suas consequências positivas na vida cultural, social e económica do País” (MCES, 2004), que a proposta ganha também uma dimensão política. Um modelo, essencialmente operacional, entrou também no debate político. ${ }^{10}$

\subsection{A proposta para um novo modelo de financiamento}

Neste contexto, entre discursos políticos e burocráticos, a ministra da Ciência e do Ensino Superior, Maria da Graça Carvalho, surpreende a comuni-

\footnotetext{
9 Já se o financiamento fosse inteiramente de origem nacional, não co-financiado por fundos comunitários, a questão colocar-se-ia apenas no plano político, de um modelo de governação.

${ }^{10}$ Um deputado da oposição, do Partido Socialista, alude claramente nesta direcção na sua coluna semanal: "Comecemos pela guerra política" (Augusto Santos Silva, "Temporal na ciência", Público, 29 de Maio de 2004).
} 
dade científica com a apresentação, em Abril de 2004, de uma proposta de um novo modelo de financiamento das unidades de investigação. Anunciado em primeiro lugar num jornal diário, o documento do MCES continha as seguintes linhas de orientação:

- incentivos para a organização da investigação em unidades de investigação de maior dimensão, para uma melhor coordenação dos recursos; - o financiamento por doutorado elegível variava em três níveis, consoante a dimensão da unidade, sendo que a dimensão mínima era também elevada de três para sete doutorados;

- um modelo de financiamento distinto, o de Laboratório Associado, era agora considerado quase em paralelo com a questão da dimensão das unidades;

- alteração da distribuição de recursos entre áreas científicas, através da introdução de áreas prioritárias, a serem definidas top-down por portaria, e de um factor de intensidade tecnológica variável com área científica; - importância central de indicadores quantitativos de publicação internacional nas bases de dados do ISI (indicadores bibliométricos);

- alteração da elegibilidade dos investigadores doutorados, a qual deixa de ser dependente do tempo dedicado à investigação na unidade para ser agora dependente dos resultados (publicações internacionais nas bases de dados do ISI ou valor de contratos);

- incentivos à cooperação com a indústria, através de factores multiplicativos com base no valor de contratos industriais ou de resultados no tocante a patentes ou spin-offs;

- prémios individuais de "estímulo à excelência" com base num patamar de publicações nas bases de dados do ISI, com incentivo suplementar à captação para Portugal de investigadores no estrangeiro;

- ausência de financiamento programático;

- finalmente, ainda que uma alteração não explicitada, os resultados da avaliação qualitativa através de painéis internacionais perdem grande parte da sua importância no volume de financiamento a atribuir a cada unidade, passando a ser um factor reduzido face a outros factores essencialmente de natureza quantitativa.

Este último ponto sintetiza o impacto do novo modelo, o qual, na prática, substitui a avaliação qualitativa por uma metodologia de avaliação maioritariamente quantitativa, tornando centrais práticas de avaliação com fraca experiência de utilização a nível nacional. Não correspondendo a um mero reajustamento do modelo anterior, e perante a inexistência de pressões para 
uma alteração significativa, mas antes de declarações de apoio à prática existente, esta reformulação de modelo de financiamento das unidades de investigação é também interpretada como uma rejeição do modelo existente e do conceito de prestação de contas subjacente. Na verdade, vários dos aspectos reformulados são parte integrantes deste conceito, tais como a preponderância da avaliação pelos pares, a inexistência de uma definição, fora da arena científica, de áreas prioritárias (um ponto de discussão política de frequente reincidência em Portugal, como noutros países), ou a ênfase nos conhecimentos produzidos enquanto resultados de um processo de produção de conhecimentos em contraponto com a ênfase no investigador enquanto recurso desse mesmo processo. Do mesmo modo, a justificação dos diferentes factores na nova proposta (que não necessariamente dos detalhes da sua formulação) pode ser entendida como a formulação de um novo conceito de prestação de contas, baseado agora na racionalização de recursos, na materialização de resultados científicos e na ligação directa, no curto prazo, à economia.

\subsection{A discussão pública da proposta}

Com a apresentação da proposta, a Ministra anunciou igualmente um processo de consulta formal e uma consulta pública através da página da internet do Ministério.

Este processo de consulta não satisfez plenamente a comunidade científica. Em primeiro lugar, a proposta, tendo por base um instrumento que muitos consideravam como central para o funcionamento do sistema, era apresentada sem anúncio prévio e sem ter sido antes discutida com os principais actores do sistema. Aparentemente, apenas um pequeno grupo de assessores teria sido consultado sobre a sua formulação. ${ }^{11}$

Em segundo lugar, o processo de consulta formal incluía um leque de entidades consultadas para além dos actores centrais do sistema de investigação, ao mesmo tempo que não incluía os Laboratórios Associados para os quais a legislação reserva um papel de consulta na formulação de política de ciência e tecnologia. ${ }^{12}$

\footnotetext{
${ }^{11}$ Do meu conhecimento, apenas um dos envolvidos referiu publicamente na imprensa ter participado no grupo de aconselhamento da ministra (Diário Económico, 20 de Abril de 2004).

12 Este papel de consulta, defendido pelos Laboratórios Associados, consta da legislação, da responsabilidade do ministro Mariano Gago, que instituiu a figura do Laboratório Associado (Decreto-Lei $n^{\circ}$ 125/99 de 20 de Abril). No entanto, esta prática não está ainda verdadeiramente institucionalizada. Os Laboratórios Associados (em número então de quinze) estão organizados colectivamente num Conselho de Laboratórios Associados (CLA) que tem contribuído activamente para fomentar debates públicos em torno de temas de política científica, e que organiza, com o patrocínio da Presidência da República, conferências periódicas sob o título "Prioridade à Ciência!". Ainda
} 
Em terceiro lugar, o período disponibilizado para a consulta pública era manifestamente reduzido (pouco mais de 15 dias), o que levantou fortes protestos em múltiplas intervenções. O seguinte comentário num artigo de opinião publicado no Público durante o período de debate é elucidativo:

Tal anúncio teve um impacte muitíssimo maior na comunicação social do que num dos seus alvos. $\mathrm{Na}$ verdade, se aquela se multiplicou em peças que incorporavam opiniões avulsas de investigadores, não testemunhei na universidade - a não ser os habituais comentários de corredor - nada que pudesse corresponder à importância pública que lhe foi atribuída. Só me surpreenderia o contrário, essencialmente por duas razões: a universidade tem uma estrutura tão pesada que o seu tempo de reacção é incompativel com o (curto) prazo de discussão anunciado e, por outro lado, a investigação passa actualmente ao lado da universidade portuguesa, enquanto instituição. ${ }^{13}$

Para além de ser elucidativa da contestação ao processo de consulta e do impacto da proposta, esta citação é também indicativa da forte divisão entre as funções de ensino e de investigação na universidade portuguesa e da inexistência de um processo de mediação através desta proposta e do seu processo de discussão com vista à formulação de um modelo da "multiversidade". ${ }^{14}$

Como referido acima, a imprensa, nomeadamente através dos jornais Público e Diário de Notícias, dedicou atenção significativa à proposta, nomeadamente aos incentivos individuais de 'Estímulo à Excelência', e à discussão por esta gerada, mesmo antes da consulta pública na internet ganhar uma maior dinâmica. Para além de várias notícias iniciais, foram publicados vários artigos de opinião sobre o tema nas páginas dos jornais.

\section{A cobertura da imprensa}

Apesar de as implicações centrais da proposta serem relativas ao financiamento das unidades de investigação, a imprensa dedicou quase exclusivamente a sua atenção ao plano de atracção de investigadores de "excelência"

que o CLA não tenha sido formalmente consultado, o secretário executivo do CLA é membro, por inerência, do Conselho Superior de Ciência, Tecnologia e Inovação, uma das entidades formalmente consultadas neste processo.

${ }^{13}$ António Amorim, "Hetero-avaliações da comunidade científica", Público, 29 de Abril de 2004; sublinhado meu.

${ }^{14} \mathrm{O}$ desenvolvimento de novas ligações entre investigação e ensino, referido em diversas contribuições para o debate público, é de particular importância no sistema português, em que as actividades de investigação são em grande parte desenvolvidas por docentes universitários em instituições privadas sem fins lucrativos, acolhidas por uma universidade, mas autónomas desta. Deve também referir-se que o financiamento geral das universidades, através do Orçamento de Estado, é essencialmente dependente do número de estudantes da universidade, não tendo, assim, qualquer relação com o desempenho em investigação. 
e à identificação destes através do número de publicações nas bases de dados do ISI. Ainda que fosse uma questão relativamente menor em toda a proposta, este plano tinha, claramente, um maior poder mediático. Contrariamente às complexas alterações ao modelo de financiamento das unidades, esta medida primava pela simplicidade. O plano de atracção da "excelência" consistia na concessão de financiamento individual para os investigadores com um número mínimo de 100 publicações nas bases de dados do ISI, ${ }^{15}$ a ser utilizado pelo investigador nas suas actividades, sem necessidade de formulação de proposta prévia de actividades a desenvolver. Este financiamento seria duplicado no caso de investigadores residentes no estrangeiro mas a radicar em Portugal, procurando assim a "captação de cérebros".

Os detalhes desta proposta específica eram claramente insuficientes e com evidentes limitações, mesmo para quem não seja muito versado em bibliometria. Os jornalistas não tardaram a explorar essas limitações, interpelando mesmo a ministra sobre a sua elegibilidade, após terem identificado (apenas parcialmente) as suas publicações. ${ }^{16}$ Deste modo, a cobertura jornalística da proposta focou quase exclusivamente esta medida, aproveitando para verificar a sua aplicabilidade a alguns dos cientistas portugueses mais conhecidos, e revelando do mesmo passo algumas das limitações da pesquisa.

Vários factores terão contribuído para o destaque concedido a esta medida nos jornais. Em primeiro lugar, a medida era apresentada com o objectivo de reverter a "fuga de cérebros", ${ }^{17}$ tema que tem ganho importância no sistema de investigação português e sido focado igualmente noutros círculos, desde a imprensa internacional às políticas europeias. Em Portugal, onde o apoio público à formação pós-graduada no estrangeiro tem uma longa tradição, existem sinais crescentes de que uma parcela significativa de doutorados recentes não regressa ao país devido à falta de oportunidades para tal. Esta medida era apresentada precisamente como tendo o objectivo de inverter esta tendência, criando incentivos para o regresso.

\footnotetext{
15 Para além das 100 publicações, eram necessárias 200 citações na mesma base de dados. Alternativamente, para investigadores que tivessem orientado 10 teses de doutoramento aprovadas, os limites correspondentes diminuíam para metade destes valores.

16 "Estou convencida de que há cerca de 100 cientistas em Portugal com mais de 100 artigos", Público, 22 de Abril de 2004. Neste caso, jornalistas e Ministra demonstraram algum desconhecimento existente sobre estas técnicas. Quando o concurso foi lançado, a ministra veio ela própria a ser contemplada com um prémio de "Estímulo à Excelência" pela sua produtividade científica. ${ }^{17}$ Um dos jornais diários de referência, o Público, tinha por título de secção dos artigos de opinião neste debate, durante todo o período, "Polémica sobre plano para combater fuga de cérebros", ainda que esses artigos por vezes fizessem apenas referências limitadas a essa medida.
} 
Em segundo lugar, a medida salientava a importância da "excelência" na ciência, tendo por título "Estímulo à Excelência". Esta não era apenas mais uma medida dirigida à comunidade científica, mas antes uma medida orientada para os cientistas de topo. Sendo cada vez mais central no jargão das políticas de investigação, a "excelência" era não só o objecto claro desta medida como também quantificada e, assim, claramente identificada. Ao mesmo tempo, o prémio correspondia a um financiamento não direccionado, precisamente a modalidade de financiamento que tem vindo a ser substituída, nomeadamente no que se refere à restante componente do modelo de financiamento das unidades de investigação.

Finalmente, a dimensão estritamente quantitativa da proposta, propunha também comparações individuais, proporcionando, assim, a jornalistas, e às páginas dos jornais, a identificação dos cientistas mais produtivos em Portugal - o "Quem é Quem na Ciência em Portugal”. Sendo que a cobertura de ciência na comunicação social portuguesa é muito dependente, tal como em outras áreas, de "estrelas", cientistas com maior reconhecimento público, estas classificações permitiam, por um lado, a identificação de novas "estrelas" e, por outro lado, a verificação directa da validade da medida, visto que os resultados quantitativos eram claros nas dúvidas que suscitavam. ${ }^{18}$

Este último aspecto é particularmente relevante. O essencial da proposta, o novo modelo de financiamento, era dirigido a "colectivos de investigação", as unidades de investigação que têm constituído o esqueleto do sistema. Mas, mesmo perante tal mudança, a imprensa preferiu realçar a medida dirigida aos investigadores individualmente e que era mais claramente quantificável. Ainda que de base quantitativa, a complexidade da fórmula de financiamento das unidades não permitia o mesmo tipo de experimentação. ${ }^{19}$ Esta base de experimentação abriu também uma base de discussão

\footnotetext{
${ }^{18}$ Na cobertura da imprensa, a validade da medida era, precisamente, "verificada" através da sua aplicação aos cientistas mais reconhecidos publicamente. Nas suas contribuições, os investigadores recorreram por vezes a exemplos de reputados investigadores internacionais para "comprovar" a falta de razoabilidade do critério. Estas "experiências" iniciais dos jornalistas tornaram também evidente a existência de questões metodológicas sobre este processo de identificação e a falta de robustez da proposta. A contribuição desta medida para o reconhecimento público dos investigadores foi salientado por uma conhecida investigadora: "Ficar a conhecer o trabalho dos investigadores mais velhos é um dos aspectos positivos da proposta do Ministério da Ciência" (in "Contagem de artigos permitirá conhecer melhor o trabalho dos investigadores", Público, 30 de Abril de 2004). Na apresentação dos premiados, a ministra frisou também o reconhecimento individual: "Publicar 100 artigos ou perto disso é uma vida dedicada à ciência e ao serviço público, no que isso tem de mais nobre, que é o desenvolvimento científico" (in "Setenta e três cientistas premiados por publicar mais de 100 artigos", Público, 26 de Novembro de 2004).

${ }_{19}$ Aliás, a partir da análise de diferentes intervenções no processo de discussão, não é claro que tenham existido estudos prévios dos resultados da aplicação do novo modelo de financiamento das unidades de investigação ou da medida de 'Estímulo à Excelência'.
} 
sobre o carácter construído dos indicadores utilizados, bem como sobre o papel da quantificação na construção de novas políticas e processos de avaliação. ${ }^{20}$

Também é de notar que, ao contrário do que poderia esperar-se na lógica do contrato social, a imprensa não valorizou a importância dada na nova proposta de financiamento das unidades à interacção com a indústria (patentes, spin-offs ou contratos), como incentivo a uma maior abertura do sistema e a um novo conceito de prestação de contas. A imprensa não só não assumiu, assim, o papel subjacente a uma redefinição do modelo de prestação de contas, identificando-o no contexto da proposta, como agiu num contexto semelhante ao da própria proposta, valorizando essencialmente a metodologia quantitativa, e a suas eventuais "evidências".

\section{As contribuições para o debate}

A proposta governamental levou a uma grande participação no processo de discussão pública. Para além das notícias sobre as medidas, que não se limitaram à apresentação da proposta, as páginas do Público e Diário de Notícias publicaram 19 artigos de opinião sobre a nova proposta. ${ }^{21}$ Ainda que estes jornais publiquem ocasionalmente artigos de opinião sobre política científica, o espaço e perfil dedicado por ocasião deste debate foi muitíssimo mais significativo, correspondendo, por vezes, a páginas inteiras do jornal.

Também o fórum criado na página de internet do MCES foi muito participado, tendo recebido 125 contribuições durante o período de discussão. ${ }^{22}$ Tendo em conta o curto período de consulta, este nível de participação foi significativo, não lhe sendo totalmente alheio o espaço dedicado na comunicação social. Um número de contribuições semelhante tinha sido recebido por ocasião de um processo de consulta, cerca de um ano antes, sobre a reforma do ensino superior em Portugal, mas por um período mais prolongado (uma síntese das contribuições foi posteriormente publicada; cf. Amaral, 2003). Um Fórum Permanente de Política de Ciência e Tecnologia, na página de internet do então Ministério da Ciência e da Tecnologia em 1998, para discutir as necessidades estratégicas do sistema de investigação com

${ }^{20}$ Cf. Porter (1995) sobre o papel dos números, e da sua "objectividade", nas políticas públicas.

${ }^{21}$ A discussão pública na imprensa não se limitou a estes dois jornais diários, mas estes foram aqui escolhidos devido ao maior número de contribuições nas suas páginas e à cobertura dedicada ao tema pelos próprios jornalistas.

${ }^{22}$ Com uma participação reduzida inicialmente (ao fim da primeira semana havia apenas 7 contribuições publicadas), esta tornou-se muito intensa no final, tendo sido recebidas metade das contribuições no último dia da consulta pública, nomeadamente todas as contribuições institucionais de universidades. 
vista à formulação do novo programa operacional para a ciência (que veio a ser o POCTI, iniciado em 2000) reunira 77 contribuições num período de 6 meses.

Estas contribuições, ainda que maioritariamente críticas da proposta, incluíram também comentários de apoio à implementação de um sistema com base em indicadores de desempenho. Os seguintes aspectos foram mais discutidos:

- a substituição da importância da avaliação qualitativa, por pares, por uma avaliação de dimensão essencialmente quantitativa;

- inconsistências dos critérios apresentados, valorizando de modo semelhante resultados da investigação com impactos muito diversos ou que resultam de investimentos, em termos de tempo, muito diferentes;

- a automatização do processo, através de fórmulas pré-definidas, criava incentivos a maximizar o retorno de financiamento e não necessariamente o impacto da investigação, podendo levar a práticas perversas de co-autoria ou de aumentar a quantidade de publicações em detrimento da qualidade;

- a proposta valorizava um conjunto limitado de actividades dos investigadores, negligenciando algumas actividades importantes;

- a reduzida aplicabilidade de alguns critérios em certas áreas científicas, nomeadamente nas ciências sociais e humanas;

- a medida destinada a combater a "fuga"/promover a "captação de cérebros” ser dirigida a cientistas seniores, já estabelecidos e com poucos incentivos para se radicarem em Portugal, quando os investigadores mais jovens necessitam de maiores oportunidades de emprego e de apoio no desenvolvimento da carreira;

- o reduzido período de consulta pública e a falta de diálogo com a comunidade científica na formulação da proposta foram aspectos muito criticados;

- a proposta foi também criticada por considerar apenas uma parte das instituições do sistema, não sendo aplicável aos laboratórios do Estado e não incluindo quaisquer elementos dirigidos especificamente para as universidades e para as suas carreiras.

$\mathrm{Na}$ discussão da proposta, os investigadores incluíram, por vezes, sugestões específicas de melhoria dos critérios (algumas das quais viriam a ser aceites mais tarde).

Muitos dos comentários reflectiam a origem disciplinar dos investigadores. O Quadro 1 é particularmente elucidativo quanto ao padrão de par- 
ticipação no debate. Das 125 contribuições para o debate público, 49 corresponderam a posições institucionais, incluindo, por exemplo, associações industriais, centros de investigação e universidades (neste último caso, a contribuição não foi atribuída a uma área científica), e as restantes foram aqui classificadas como sendo de carácter individual. A maior participação correspondeu à área das ciências exactas, com $26,1 \%$ das contribuições classificadas por área científica.

Apresentando, para termos comparativos, a distribuição de doutorados nas unidades de investigação em Portugal, é, assim, claro que as Ciências Sociais, contabilizando $25 \%$ das contribuições classificadas por área e representando 16,5\% dos doutorados, e as Ciências Exactas, com 26,1\% das contribuições para 20,1\% dos doutorados, são as áreas com participação superior à sua distribuição no país. ${ }^{23}$

QUADRO 1 - Número de participações na consulta pública no sítio do MCES por Área Científica

\begin{tabular}{|c|c|c|c|c|c|}
\hline Área Científica & $\begin{array}{l}\text { Participações } \\
\text { Individuais }\end{array}$ & $\begin{array}{l}\text { Participações } \\
\text { Institucionais }\end{array}$ & $\begin{array}{c}\text { Total de } \\
\text { Participações }\end{array}$ & $\begin{array}{l}\text { \% do Total de } \\
\text { Participações }\end{array}$ & $\begin{array}{l}\text { \% do Total de } \\
\text { Doutorados* }\end{array}$ \\
\hline Artes e Humanidades & 5 & 5 & 10 & $10,9 \%$ & $11,9 \%$ \\
\hline Ciências Sociais & 13 & 10 & 23 & $25,0 \%$ & $16,5 \%$ \\
\hline Ciências Exactas & 14 & 10 & 24 & $26,1 \%$ & $20,1 \%$ \\
\hline Engenharia e Tecnologia & 8 & 5 & 13 & $14,1 \%$ & $21,6 \%$ \\
\hline Ciências da Saúde & 5 & 2 & 7 & $7,6 \%$ & $10,4 \%$ \\
\hline Ciências Naturais & 11 & 6 & 17 & $18,5 \%$ & $19,5 \%$ \\
\hline Não classificadas & 22 & 11 & 33 & $(26,4 \%)$ & - \\
\hline$\overline{\text { Total }}$ & 76 & 49 & 125 & $100 \%$ & $100 \%$ \\
\hline
\end{tabular}

* Fonte: Base de dados de unidades de investigação, em www.fct.mces.pt

De entre a principal argumentação utilizada, estas duas áreas salientaram três questões principais (houve alguma sintonia de posição entre as Ciências Sociais e as Artes e Humanidades).

Em primeiro lugar, estas contribuições consideraram que as bases de dados do ISI não eram a melhor fonte para identificar o trabalho de qualidade realizado nestas áreas de investigação. $\mathrm{Na}$ verdade, as bases do ISI, ainda que incluindo todas as áreas, apresentam uma melhor cobertura das ciências da saúde e naturais (áreas que têm também tradicionalmente um número mais elevado de citações), ainda que grande parte das ciências

${ }^{23}$ A classificação teve por base as áreas e grandes áreas científicas utilizadas pela Fundação para a Ciência e Tecnologia na base de dados de unidades de investigação. 
exactas, ao contrário das engenharias e tecnologias, apresentem também uma cobertura adequada. Conforme discutido por Hicks (1999), as ciências sociais apresentam maior dificuldade de cobertura, devido à sua heterogeneidade e orientação nacional.

Em segundo lugar, o entendimento de impacto da investigação subjacente na proposta incluía uma noção de transferência de tecnologia essencialmente incorporada em patentes e spin-offs, enquanto uma visão mais alargada de transferência de conhecimento, menos centrada em produtos jurídicos, deveria incluir actividades de extensão típica de outras áreas (por exemplo, a participação em comités consultivos, o aconselhamento a políticas públicas, os programas informáticos; cf. Mollas-Galart et al., 2002).

Em terceiro lugar, a valorização proposta de participação em redes internacionais coloca ênfase nas colaborações com o Norte, menosprezando, assim, a participação em redes internacionais com países do Sul. Não só existem boas razões no plano nacional para se desenvolverem estas colaborações, como elas são também importantes plataformas para a transferência de saberes, o que a proposta procura incentivar.

Pelo contrário, é de notar como as Ciências da Saúde (7,6\% de participações para 10,4\% de doutorados) e as Engenharias e Tecnologias (14,1\% de participações para 21,6\% de doutorados) são as áreas com participação particularmente inferior ao eventualmente esperado. Este facto é particularmente de notar quando os investigadores da área das Ciências da Saúde têm sido muito activos em discussões públicas sobre ciência em Portugal, e quando, nesta área, apenas um centro de investigação (pertencente a um Laboratório do Estado) não financiado por este programa e uma empresa apresentaram posições institucionais.

No que não será totalmente irrelevante, esta área, em Portugal como no estrangeiro, tem uma elevada parcela de publicações ISI e uma elevada frequência de publicação (ainda que com variações entre domínios específicos). ${ }^{24} \mathrm{Na}$ verdade, uma grande parte dos primeiros investigadores a quem foi atribuído o Prémio de "Estímulo à Excelência" era precisamente desta área científica. ${ }^{25}$ É também nesta área que mais se tem desenvolvido em anos recentes o patenteamento académico e uma maior proximidade entre o mundo académico e da indústria (cf. Mowery et al., 2001).

Já no caso dos investigadores da área da Engenharia e Tecnologia, que também participaram menos do que se poderia esperar com base no res-

\footnotetext{
${ }^{24} \mathrm{Na}$ cobertura da imprensa foram identificados alguns cientistas nas área de Ciências da Saúde e de Engenharia Química com mais de 100 publicações ISI.

${ }^{25}$ Lista disponível em www.fct.mces.pt.
} 
pectivo número de investigadores, os indicadores de publicações ISI nem sempre lhes serão muito favoráveis (dependendo da área), mas estarão certamente em maior sintonia com um aumento dos incentivos à investigação aplicada e ligação com a indústria.

Estas variações por área, e o modo como reflectem tendências actuais dos discursos políticos e da emergência de sectores de maior potencial económico, reflectidas na menor participação dos próprios investigadores no processo de consulta, um processo maioritariamente crítico, configura o contexto da emergência de novos modelos da relação entre ciência e política. Assim, este caso não é apenas um estudo de "política de investigação" mas também das "novas políticas na investigação". ${ }^{26}$

Esta diferenciação entre áreas científicas, com consequências na distribuição futura de financiamentos, não é nova. Geuna e Martin (2003) ${ }^{27}$ analisaram em detalhe as vantagens e limitações de diferentes mecanismos de financiamento e de avaliação, desde os modelos com base unicamente no desempenho anterior a modelos com base no número de estudantes inscritos (distinções que não cabe aqui enunciar). Da sua análise dos modelos com base no desempenho ressalta que, ainda que seja importante a recompensa do sucesso e a ligação directa entre política (ou financiamento) e investigação, melhorando a prestação de contas, existem também nestes modelos aspectos negativos não negligenciáveis. Podem encorajar a homogeneização da investigação e isomorfismos institucionais por via de uma optimização dos resultados e de processos miméticos e podem levar a aumentar a separação entre ensino e investigação, particularmente quando os prémios para esta última actividade são mais elevados do que para o ensino. Importa, assim, garantir que uma política com base no desempenho minimize estes impactos negativos, instituindo os incentivos adequados a uma distribuição equilibrada, ainda que não equitativa, de recursos.

\subsection{O modelo de financiamento aprovado}

Após o período de consulta, e com base nas contribuições recebidas, o Ministério introduziu alterações à proposta inicial e aprovou o novo modelo de financiamento. Neste processo não houve novas interacções com a comunidade científica ou mesmo uma comunicação da decisão final, para além da publicação na página de internet do Ministério em conjunto

\footnotetext{
${ }^{26}$ Esta diferenciação é claramente mais feliz na língua inglesa, distinguindo-se entre 'research policies' e o que pretendo aqui identificar como 'new politics of research'.

${ }_{27}$ Martin e Irvine (1983) apresentam exaustivamente o potencial da utilização de indicadores bibliométricos na avaliação de investigação, as suas limitações e algumas medidas eventualmente a tomar para as ultrapassar.
} 
com informação sobre 13 outras iniciativas, sem qualquer chamada de atenção particular, tendo em conta a discussão suscitada pela proposta inicial. $^{28}$

A nova proposta, ainda que mantendo os princípios básicos de ruptura com o modelo vigente, incluía alterações significativas em resposta a algumas das críticas formuladas, que se sintetizam de seguida:

- os resultados dos Painéis de Avaliação foram valorizados, através de três mecanismos:

- o valor do financiamento de base, directamente dependente da avaliação do Painel, aumentou enquanto a influência dos factores complementares decresceu;

- um dos factores quantitativos propostos, com base nas publicações, passou a ser apenas fornecido aos painéis de avaliação, como elemento de informação, deixando assim de ter um impacto directo no financiamento a atribuir;

- os painéis de avaliação passaram a decidir o valor de dois outros factores complementares, ainda que com base em indicadores pré-estabelecidos, enquanto o factor relativo às áreas prioritárias foi removido da fórmula;

- a elegibilidade dos doutorados foi flexibilizada;

- em resposta às críticas de algumas áreas, foi dada maior atenção a especificidades disciplinares, nomeadamente no que se refere às fontes de dados sobre publicações, a definir posteriormente para algumas áreas (entre as quais as Ciências Sociais e Humanidades e as Ciências Exactas);

- outros detalhes (mas não ainda de forma exaustiva) foram clarificados.

O perfil público do debate e a participação activa da comunidade científica no processo de consulta pública tornara inevitável uma revisão da proposta inicial. Ainda que a aprovação do novo modelo não tenha sido publicitada ou discutida, é no entanto claro que a proposta aprovada manterá em parte os seus críticos, que irão certamente considerar que as alterações introduzidas são diminutas relativamente à reconfiguração do modelo de prestação de contas do sistema de investigação que ela pressupõe e à dinâmica criada em torno de uma nova política na investigação.

\footnotetext{
${ }^{28}$ Após a atenção inicial dedicada a este debate, a imprensa não noticiou a aprovação final do novo modelo de financiamento. Veio mais tarde a noticiar os resultados da iniciativa de "Estímulo à Excelência”, com perfis de alguns dos premiados, precisamente numa lógica de reconhecimento público do trabalho realizado.
} 


\subsection{Discussão}

O caso aqui analisado apresenta ingredientes vários para a discussão não só de modelos de governação da ciência e da prestação de contas que lhes está subjacente, como também do próprio processo de formulação de políticas públicas nesta área. Não se pretendeu aqui apresentar uma avaliação de modelos de financiamento e dos seus impactos, ainda que seja claro que existem vantagens e desvantagens nos diferentes modelos de financiamento e, em particular, na sua regulamentação.

Todo o processo de apresentação da proposta, e do seu debate público, deixa em aberto uma questão a que esta análise não pretendeu responder directamente. $\mathrm{O}$ caso apresentado torna claro que a proposta foi largamente criticada pelos principais interessados, os investigadores, quer num plano estratégico, quer quanto aos pormenores da implementação. Por outro lado, não só não havia movimentos anteriores no sentido de que emergisse uma nova proposta como veio a acontecer, como a sua formulação não beneficiou de uma interacção prévia com a comunidade científica e mostrou sinais de inconsistência e falta de robustez. A proposta foi, no entanto, apresentada, (brevemente) discutida, e aprovada. Como foi, pois, possível que o processo avançasse apesar destes condicionalismos?

A discussão sugere que há uma evolução global de modelos de governação da ciência na direcção da proposta apresentada, enfatizando os benefícios económicos da investigação, os seus resultados directos, a quantificação de resultados, uma redução da autonomia dos investigadores e uma maior co-responsabilização do Estado no rumo a dar à ciência. É este contexto político que permite que apesar da oposição à proposta e da existência de algumas insuficiências a proposta seja identificada, num sentido genérico, com outros desenvolvimentos das políticas de investigação, criando assim uma dinâmica que transcende as fronteiras do sistema, com a sua própria base de apoio. encaminhamento

Num segundo plano, na discussão pública da proposta evidencia-se igualmente uma outra configuração das "novas políticas na investigação", que envolvem também de modo diferenciado as áreas científicas. Neste sentido, podem de certo modo considerar-se as ciências da saúde como o exemplo central das novas dinâmicas de investigação. A questão que é aqui levantada é também se este modelo pode ser implementado transversalmente a outras áreas científicas. A discussão acima sugere que não é assim e que as políticas de investigação deverão considerar os diferentes perfis de investigação. 


\section{Conclusão}

Algumas conclusões podem ser formuladas com base no debate público da proposta do novo modelo de financiamento das unidades de investigação em Portugal e na análise anterior. Em primeiro lugar, ainda que os investigadores portugueses não contribuam activamente para uma discussão em espaços públicos de questões de política científica, tornou-se claro que, quando estas propostas têm implicações directas para a atribuição de financiamentos ou para a valorização das suas actividades, os investigadores empenham-se, quer individual, quer institucionalmente. Perante um impacto potencial significativo da proposta apresentada, houve uma participação elevada, nomeadamente tendo em conta experiências anteriores de consulta pública, com um debate detalhado da proposta e da estratégia subjacente.

Este nível de participação torna evidente que os investigadores necessitam de dialogar sobre as políticas de ciência, como concluiu também Norma Morris no seu estudo sobre a influência de determinadas políticas (em Inglaterra) nos investigadores e líderes de grupos de investigação: "as agências de financiamento poderão estar interessadas [...] em melhorar o diálogo com os investigadores universitários no laboratório" (Morris, 2000: 450). Como referido num artigo de opinião por um investigador reclamando maior diálogo: "Se há, no entanto, hoje em dia, domínio em que não é possível avançar isolado e sem uma rede consistente de articulações é o científico." 29

No caso presente, tornou-se claro que, para além da apresentação pública da proposta e da abertura do processo de consulta, houve poucos esforços da parte do MCES para se envolver em diálogo e explicar as medidas apresentadas. Esta falta de diálogo é particularmente relevante quando a apresentação da proposta, em substituição de um modelo com sucesso que não tinha sido alvo de críticas públicas significativas, não foi previamente justificada.

A apresentação da proposta pelo ministério, e não através da agência de financiamento ${ }^{30}$ que organizou até aqui o processo de avaliação, revela que o potencial papel de intermediação desta, enquanto organização de fronteira, tal como sugerido por Nowotny et al. (2001), não está a ser preenchido e não separa a estratégia política dos detalhes da sua implementação. Corre-se, assim, o risco de os investigadores, rejeitando os detalhes de implementação, rejeitarem também a justificação genérica subjacente.

\footnotetext{
${ }_{29}$ Diogo Pires Aurélio, "Dados da ciência”, Diário de Notícias, 17 de Abril de 2004.

${ }^{30}$ A Fundação para a Ciência e Tecnologia, ainda que siga um modelo próximo dos de Conselhos de Investigação de outros países europeus, está sob a tutela directa do respectivo ministério, neste caso, o Ministério da Ciência, Inovação e Ensino Superior.
} 
Em segundo lugar, como discutido anteriormente, um dos temas centrais destes processos de avaliação está relacionado com a questão de os critérios de avaliação poderem ser aplicados a diferentes perfis de actividade ou tenderem a encorajar homogeneização, como referido por Geuna e Martin (2003).

A discussão acima revela que a interpretação pelos investigadores dos incentivos subjacentes à proposta, evidenciada nas suas contribuições na consulta pública, pode tornar-se monolítica, salientando quase unicamente uma direcção de sucesso: a publicação em quantidade (e utilizando os diversos mecanismos para a potenciar), levando a que sejam suscitadas dúvidas como a que se segue: "Resta saber qual a verdadeira utilidade da sua investigação para o país." 31

Tendo em conta os baixos níveis de sucesso na comercialização da investigação em Portugal, o incentivo suplementar para estes resultados pode também ser entendido como um joker, de maior valor devido ao seu reduzido número. Mas esta leitura também significa que outros grupos de investigação, que têm sido muito activos em actividades de extensão de diversos tipos, nomeadamente de divulgação pública da ciência ou em comités públicos de aconselhamento, não têm incentivos significativos para continuar essas actividades.

Deste modo, nesta proposta a visão da "sociedade do conhecimento" sobrepõe-se claramente à da "sociedade de risco", na tensão identificada por Nowotny et al. (2001). O modelo final aprovado atenuou esta preponderância, mais através da redução das assimetrias entre resultados do processo do que através da revalorização de outras actividades.

A visão de Clark Kerr da multiversidade, anteriormente referida, reflectia desde logo esta tensão central. Derek Bok (2003), outro ex-presidente de uma conceituada universidade americana (neste caso, a universidade privada de Harvard), adverte também de modo semelhante para as tensões com que se depara a universidade, com dificuldade em resistir à visão empresarial e às receitas financeiras que estas parcerias prometem. Não resistindo a esta via, a universidade reduz precisamente a capacidade de manter a sua diversidade e de explorar a sua multiplicidade de funções, em troca de um objectivo central que acabará por levá-la a ficar refém dos actores industriais. Como referido por Bok, "as fortes ligações entre a ciência universitária e a indústria geram vários formas de risco de se comprometer a transparência, objectividade e independência da investigação académica" (Bok, 2003: 156).

${ }^{31}$ Pedro Fevereiro, “A ciência e o seu financiamento”, Público, 29 de Abril de 2004. 
Ainda que este seja um estudo de uma iniciativa política muito específica, o caso apresentado levanta questões sobre a capacidade das agências financiadoras de agirem como organizações de fronteira no meio do discurso político dominante. Haverá uma tendência para um maior intervencionismo do Estado no sentido de orientar as políticas de investigação para a inovação ou este caso tem apenas uma especificidade nacional? Sem a tradição de envolvimento de actores industriais, ou mesmo de outros actores sociais, podem agências financiadoras ter um papel de intermediação, quando estão em causa políticas de competitividade, ou serão inevitavelmente cooptadas pelo discurso político dominante?

Finalmente, o que está também aqui em causa é a capacidade da política científica de ser ela própria objecto de democratização (Kleinman, 2000). Como defendi noutro texto, este é um dos paradoxos dos estudos de inovação: "quanto melhor compreendemos a inovação, mais difícil se torna traduzir este conhecimento para a formulação de políticas e os decisores públicos" (Pereira, 2002). Quando o discurso sobre a "sociedade baseada no conhecimento" se propaga para outros sectores da administração, que se tornam cada vez mais conscientes da importância das actividades de produção de conhecimento, revela-se difícil evitar que esta importância seja simplificada, perdendo-se a noção da heterogeneidade do processo de inovação e da diversidade de actores envolvidos.

Está, no entanto, lançado o desafio de sermos capazes de desenvolver indicadores e metodologias sociais capazes de considerar os impactos diversificados da investigação, envolvendo não apenas cientistas e empresários, mas também outros grupos sociais e, finalmente, os cidadãos (Jasanoff, 2003; Leydesdorff e Etzkowitz, 2003; Santos, 2004). Tem havido tentativas de identificar novos indicadores que consideram esta diversidade de actividades (e.g. Mollas-Gallart et al., 2002), mas há ainda um longo caminho a percorrer para se atingir uma participação alargada do público em geral nos processos de governação da ciência, criando, assim, incentivos adequados a essa participação e, ao mesmo tempo, uma visão integrada do papel da universidade e dos diferentes objectivos da investigação.

\section{Referências Bibliográficas}

Amaral, Alberto (2003), "Avaliação, revisão e consolidação da legislação do Ensino

Superior”. Porto: CIPES (http://www.mces.pt/docs/ficheiros/Avaliacao, Revisao e Consolidacao da Legislacao do ES.pdf, acedido em 15/07/03).

Bok, Derek (2003), The University in the Marketplace. Cambridge: Polity Press. 
Bush, Vannevar (1945), Science: The Endless Frontier. Washington, D.C.: Office of Scientific Research and Development (disponível em http://www.nsf.gov/od/lpa/ nsf50/vbush1945.htm).

Comissão Europeia (2003), “Auditoria de sistemas efectuada em Portugal ao POCTI”. Bruxelas: Direcção-Geral de Política Regional, Comissão Europeia (mimeo).

Dasgupta, Partha; David, Paul A. (1994), "Towards a New Economics of Science”, Research Policy, 23, 487-521.

FCT (2004), “Avaliação Unidades I\&D - Descrição Geral do Programa”, www.fct. mces.pt/pt/apoios/unidades/avaliacaounidades/descricao/, acedido em 15/11/04).

Geuna, Aldo; Martin, Ben R. (2003), "University Research Evaluation and Funding: An International Comparison”, Minerva, 41, 277-304.

Gibbons, Michael et al. (1994), The New Production of Knowledge: The Dynamics of Science and Research in Contemporary Societies. London: Sage.

Gieryn, Thomas F. (1995), "Boundaries of Science", in Sheila Jasanoff et al. (orgs.), Handbook of Science and Technology Studies. Thousand Oaks: Sage.

Guston, David (2000), Between Politics and Science: Assuring the Integrity and Productivity of Research. Cambridge: Cambridge UP.

Hicks, Diana (1999), "The Difficulty of Achieving Full Coverage of International Social Science Literature and the Bibliometric Consequences”, Scientometrics, 44(2), 193-215.

Jasanoff, Sheila (2003), "Technologies of Humility: Citizen Participation in Governing Science”, Minerva, 41, 223-244.

Kerr, Clark (1995), The Uses of the University. Cambridge. MA: Harvard UP [5 $5^{\text {ed.; }}$ $\left.{ }^{1} 1963\right]$.

Kleinman, Daniel Lee (org.) (2000), Science, Technology \& Democracy. Albany: State University of New York Press.

Leydesdorff, Loet; Etzkowitz, Henry (2003), "Can 'The Public' Be Considered as a Fourth Helix in University-Industry-Government Relations?”, Science and Public Policy, 30(1), 55-61.

Martin, Ben R.; Irvine, John (1983), “Assessing Basic Research: Some Partial Indicators of Scientific Progress in Radio Astronomy”, Research Policy, 12, 61-90.

MCES (2004), "Sistema Científico, Tecnológico e de Inovação: Modelo de financiamento”. Lisboa: Ministério da Ciência e do Ensino Superior (mimeo).

Mollas-Gallart, Jordi et al. (2002), Measuring Third Stream Activities: Final Report to the Russel Group of Universities. Brighton: SPRU, University of Sussex.

Morris, Norma (2000), "Science Policy in Action", Minerva, 38, 425-451.

Mowery, David C. et al. (2001), "The Growth of Patenting and Licensing by U.S. Universities: An Assessment of the Effects of the Bayh-Dole Act of 1980", Research Policy, 30, 99-119.

Nowotny, Helga; Scott, Peter; Gibbons, Michael (2001), Re-Thinking Science: Knowledge and the Public in an Age of Uncertainty. Cambridge: Polity Press. 
OECD (2003a), The Governance of Public Research. Paris: Organisation for Economic Co-operation and Development.

OECD (2003b), Turning Science into Business: Patenting and Licensing at Public Research Organisations. Paris: Organisation for Economic Co-operation and Development. Pavitt, Keith (1991), "What Makes Basic Research Economically Useful?”, Research Policy, 20, 109-119.

Pereira, Tiago Santos (2002), "The Social Contract for Science and the Models for Academic Research: Implications for the Governance of Science in the Periphery", comunicação apresentada à NPRNet Conference, 21-23 de Março de 2002, Universidade de Sussex, Brighton.

Pereira, Tiago Santos (2004), "Science Policy Making, Democracy and Changing Knowledge Institutions”, International Social Science Journal, 180, 245-256.

Polanyi, Michael (1962), "The Republic of Science, Its Political and Economic Theory", Minerva, 1, 54-73.

Porter, Theodore (1995), Trust in Numbers: The Pursuit of Objectivity in Science and Public Life. Princeton: Princeton UP.

Salter, Ammon; Martin, Ben (2001), “The Economic Benefits of Publicly Funded Basic Research: A Critical Review”, Research Policy, 30(3), 509-532.

Santos, Boaventura de Sousa (1994), Pela mão de Alice: O social e o político na pós-modernidade. Porto: Afrontamento.

Santos, Boaventura de Sousa (2004), A universidade no século XXI: Para uma reforma democrática e emancipatória da Universidade. São Paulo: Cortez.

Slaughter, Sheila; Rhoades, Gary (1996), "The Emergence of a Competitiveness Research and Development Policy Coalition and the Commercialization of Academic Science and Technology", Science, Technology \& Human Values, 21, 303-339.

Soo, Mary; Carson, Cathryn (2004), "Managing the Research University: Clark Kerr and the University of California”, Minerva, 42, 215-236. 